\title{
Epidemiology of virus-induced asthma exacerbations: with special reference to the role of human rhinovirus
}

\author{
Takeshi Saraya' , Daisuke Kurai ${ }^{1}$, Haruyuki Ishii ${ }^{1}$, Anri Ito ${ }^{1}$, Yoshiko Sasaki ${ }^{2}$, Shoichi Niwa ${ }^{2}$, \\ Naoko Kiyota $^{3}$, Hiroyuki Tsukagoshi ${ }^{2}$, Kunihisa Kozawa ${ }^{2}$, Hajime Goto ${ }^{1}$ and Hajime Takizawa ${ }^{1}$ * \\ 1 Department of Respiratory Medicine, School of Medicine, Kyorin University, Mitaka, Tokyo, Japan \\ ${ }^{2}$ Gunma Prefectural Institute of Public Health and Environmental Sciences, Gunma, Japan \\ ${ }^{3}$ Kumamoto Prefectural Institute of Public Health and Environmental Sciences, Kumamoto, Japan
}

\section{Edited by:}

Hirokazu Kimura, National Institute of Infectious Diseases, Japan

\section{Reviewed by:}

Akihide Ryo, Yokohama City

University, Japan

Kaoru Okazaki, Shikoku Medical

Center for Children and Adults, Japan

Tomoo Kishaba, Okinawa Chubu

Hospital, Japan

\section{*Correspondence:}

Hajime Takizawa, Department of Respiratory Medicine, School of

Medicine, Kyorin University, 6-20-2

Shinkawa, Mitaka, Tokyo 181-8611,

Japan

e-mail: hajime@ks.kyorin-u.ac.jp
Viral respiratory infections may be associated with the virus-induced asthma in adults as well as children. Particularly, human rhinovirus is strongly suggested a major candidate for the associations of the virus-induced asthma. Thus, in this review, we reviewed and focused on the epidemiology, pathophysiology, and treatment of virus-induced asthma with special reference on human rhinovirus. Furthermore, we added our preliminary data regarding the clinical and virological findings in the present review.

Keywords: epidemiology, pathophysiology, treatment, human rhinovirus, asthma exacerbation

\section{INTRODUCTION}

More than 200 different types of viruses, such as human rhinovirus (HRV), human metapneumovirus (HMPV), respiratory syncytial virus (RSV), and human parainfluenza virus (HPIV), are known to cause acute respiratory illness (ARI; Tsukagoshi et al., 2013). We recently reported the issue of "virus-induced exacerbation in asthma and chronic obstructive pulmonary disease" (Kurai et al., 2013a), however, among these causative viruses, HRV is now recognized to have a major impact on asthma pathogenesis (Fujitsuka et al., 2011). From this perspective, we reviewed the literature regarding the epidemiology of HRV-induced asthma in adults, together with preliminary epidemiological data obtained at our institution.

\section{CLINICAL VIROLOGY OF HUMAN RHINOVIRUS}

HRV belongs to the genus Enterovirus and family Picornaviridae (Turner and Couch, 2007). HRV possesses a single strand positive-sense RNA (ssRNA) genome of approximately $7.2 \mathrm{~kb}$. The viral capsid is composed of four viral proteins (VP1-4) which are assembled into 60 protomers, resulting in a small icosahedral structure with a diameter of about $28-30 \mathrm{~nm}$ (Turner and Couch, 2007). Genetically, HRV is classified into three species; HRV-A, -B, and -C (Simmonds et al., 2010). Furthermore, these species of HRV have more than 150 genotypes (Andries et al., 1990; Arakawa et al., 2012; Kiyota et al., 2013, 2014). Molecular epidemiological studies suggest that the dominant species are HRV-A and -C, while HRV-B is relatively rarely detected (Arakawa et al., 2012; Kiyota et al., 2013). In particular, the VP1 and VP2 proteins have variations in their amino acid sequences, accounting for the large number of viral serotypes (Turner and Couch, 2007). The host receptor for HRV in respiratory epithelial cells is the intracellular adhesion molecule 1 (ICAM-1, CD54) for the 84 major HRV serotypes (HRV-A and -B), or low-density lipoprotein receptor (LDLR) for the other minor HRV serotypes. The receptor for HRV-C is not yet known. It has been suggested that the optimal temperature for replication of $\mathrm{HRV}$ is relatively cool $\left(33-35^{\circ} \mathrm{C}\right)$, which would limit infections to the upper airway; however, large or medium sized airways lower in the respiratory tract are now also considered cool enough for HRV replication, in spite of the higher temperature of the lung parenchyma $\left(37^{\circ} \mathrm{C}\right.$; McFadden et al., 1985). Therefore, HRV is potentially a causative agent of more severe ARI such as bronchiolitis and pneumonia (Turner and Couch, 2007; Watanabe et al., 2010; Smuts et al., 2011; Arakawa et al., 2012), and may be associated with virus-induced asthma (Johnston et al., 1995; Linsuwanon etal., 2009; Fujitsuka et al., 2011; Smuts et al., 2011). HRV might therefore be involved in various ARIs and additional respiratory complications (Kiyota et al., 2013). Lieberman et al. (2009) reported that the detection of any virus include HRV, the sensitivity rates for nasopharyngeal swab (73.3\%) was superior than that of oropharyngeal swab (54.2\%), respectively.

\section{VIRUS-INDUCED COLDS AND THEIR NATURAL COURSE AMONG THE GENERAL POPULATION}

The common cold is the third most common primary diagnosis in office visits (Hsiao et al., 2010), and this disease is generally selflimiting, usually lasting up to 10 days (Fashner et al., 2012). Among the general population, HRV infection causes common colds at a frequency of 25-53\% (Makela et al., 1998; van GageldonkLafeber et al., 2005). Tyrrell et al. (1993) reported that intranasal 
inoculation with either HRV serotypes 2, 9, and 14, coronavirus type 229E, or RSV in healthy volunteers induced patterns of symptom development which were not substantially different from each other. However, individual signs or symptoms occurred earliest in HRV infections, then in coronavirus, and lastly in RSV, appearing up to 5 days after inoculation, which demonstrated the long incubation periods of RSV in volunteers (Tyrrell et al., 1993).

HRV has been implicated in patients with acute otitis media, exacerbation of chronic obstructive pulmonary disease, common cold, and lower respiratory tract infections in neonates, the elderly and immunocompromised. Arruda et al. (1997) researching the frequency and natural history of HRV infections in adults during autumn, demonstrated that the first symptom noticed most often was sore throat (40\%) in HRV culture- or PCR-positive patients, and stuffy nose in HRV-negative patients (27\%), using nasal wash specimens. Respiratory symptoms typically develop after 1-2 days after inoculation in studies, and uncomplicated HRV infections usually peak 2-4 days after inoculation. The median duration of HRV colds is 1 week, but up to $25 \%$ last more than 2 weeks (Gwaltney et al., 1967; Rotbart and Hayden, 2000). It should be noted that in illness caused by HRV, viral shedding occurs naturally for up to 21 days, but predominantly over a 3-4 days period.

\section{HRV INFECTION AMONG ASTHMATICS: IN VIVO OR IN VITRO EXPERIMENTAL STUDIES}

HRV-A type16 (HRV-16), a major group virus commonly used for experimental human infection, and HRV-A typel (HRV-1), which has been used in animal models of HRV infection, are closely related. Grunberg et al. (1999) reported that experimental HRV-16 infection via nasal inhalation leads to a transient decrease of $\mathrm{FEV}_{1.0}$ in patients with asthma, and this decreased lung function was correlated with enhanced cold symptoms and / or airway hyperresponsiveness. Contoli et al. (2006) demonstrated that type III interferon (IFN- $\lambda$ ) production levels in ex vivo cell cultures derived from bronchial epithelial cells (BECs) and macrophages obtained from asthmatic patients, were lower than in those derived from healthy controls. Furthermore, deficient interferon- $\lambda$ production was correlated with HRV viral load, severity of clinical symptoms and $\mathrm{FEV}_{1.0}$. Message et al. (2008) demonstrated that the severity of intranasally inoculated HRV-induced clinical illness in asthmatic subjects was correlated to virus load and lower airway virus-induced inflammation.

On the other hand, DeMore et al. (2009) reported that no difference in clinical symptoms, and patterns of viral shedding, was noted between subjects with persistent allergic asthma and healthy subjects after experimental infection with HRV. These different results after experimental HRV infection in individual studies in asthmatic patients and healthy subjects might be dependent on the severity of the asthma of those subjects who enrolled in the studies. Indeed, in several reports, neither defective IFN induction by HRV, nor increased HRV replication was observed in primary human BECs derived from subjects with well controlled asthma (LopezSouza et al., 2009; Bochkov et al., 2010; Sykes et al., 2014). A few animal models for rhinovirus infection have been showed because a major group of HRV (i.e., HRV-16) did not bind mouse ICAM1. Only a minor group of HRV (i.e., HRV-1B) infected the mouse.
In this regard, Bartlett et al. (2008) generated a transgenic BALB/c mouse expressing a mouse-human ICAM-1 chimeric receptor for HRV-16 infection. This study also showed asthma exacerbation model by intraperitoneally sensitized with ovalbumin with aluminum hydroxide followed by intranasal inoculation of HRV-1B or UV-inactivated HRV-1B.

\section{HRV AND ASTHMA EXACERBATIONS: CLINICAL FINDINGS}

Although data regarding virus respiratory infections (VRIs) as precipitators of asthma attacks in adults are less clear, Nicholson et al. (1993) reported that VRIs are as commonly linked to exacerbations in adults as they are in children (Johnston et al., 1996; Fujitsuka et al., 2011). This study showed that viruses were detected in 44\% of clinical exacerbative episodes with a decrease in peak expiratory flow rate (PEFR) of $50 \mathrm{~mL} /$ minute or more, and the most commonly identified virus was HRV, followed by coronaviruses and parainfluenza viruses (Nicholson et al., 1993). Thus, the virus most commonly detected in asthma exacerbations appears to be HRV.

Although HRV is well known as the most frequent cause of the common cold, the implications of HRV infection vary according to respiratory diseases. Table 1 shows the frequency of HRV infection in various adult respiratory diseases such as exacerbation of asthma (Nicholson et al., 1993; Atmar et al., 1998; Tan et al., 2003), common cold (Makela et al., 1998; van GageldonkLafeber et al., 2005), exacerbation of COPD (Seemungal et al., 2001; Rohde etal., 2003; Tan et al., 2003; Beckham et al., 2005; Papi et al., 2006; Hutchinson et al., 2007; Ko et al., 2007; McManus et al., 2008; Kherad et al., 2010; Dimopoulos et al., 2012; Perotin et al., 2013), community acquired pneumonia (Jennings et al., 2008; Johnstone et al., 2008; Johansson et al., 2010; Lieberman et al., 2010; Fry et al., 2011; Wootton et al., 2011; Luchsinger et al., 2013; Takahashi etal., 2013; Huijskens etal., 2014), exacerbation of idiopathic pulmonary fibrosis (Wootton et al., 2011), and asymptomatic infection (Fry et al., 2011).

The risk of exacerbations of asthma in adults is elevated after children return to school, and around December 25th (the Christmas holiday in westernized countries), and this is likely to be due to social interactions with children at these times. Prospective monitoring studies using reverse transcription polymerase chain reaction (RT-PCR) indicate that as many as $85 \%$ of acute asthma exacerbations in children, and about $60 \%$ in adults, were associated with the presence of upper respiratory tract (URT) infections. Corne et al. (2002) found that the detection rates of HRV in asthmatic $(10.1 \%)$ and healthy participants $(8.5 \%)$ were similar, but the LRT symptoms were significantly more severe and longer lasting in the asthmatic group than in the healthy group based on one definition of URT and LRT symptoms (Table 2; Johnston et al., 1995).

There is no common antigen across all strains of HRVs; therefore, no reliable diagnostic method for HRV infection has been established using HRV antigens or HRV-specific antibody. Although viral culture is the conventional method for HRV detection, culture methods are not practical in clinical settings for the detection of HRV, because of its slow growing character and requirement for specific culture conditions. Furthermore, the diagnostic capability of molecular amplification techniques 
Table 1 | HRV infection and its frequency in acute and chronic respiratory diseases in adults.

\begin{tabular}{|c|c|c|}
\hline & Frequency (\%) & Reference \\
\hline Exacerbation of asthma & $26-36$ & Nicholson etal. (1993), Tan etal. (2003), Atmar et al. (1998) \\
\hline Common cold & $25-53$ & Makela etal. (1998), van Gageldonk-Lafeber etal. (2005) \\
\hline Exacerbation of COPD & $3-27$ & $\begin{array}{l}\text { Tan etal. (2003), Perotin etal. (2013), Rohde etal. (2003), Seemungal etal. (2001), Papi et al. (2006), } \\
\text { Hutchinson etal. (2007), Ko et al. (2007), McManus etal. (2008), Kherad et al. (2010), Dimopoulos } \\
\text { et al. (2012), Beckham et al. (2005) }\end{array}$ \\
\hline $\begin{array}{l}\text { Community-acquired } \\
\text { pneumonia }\end{array}$ & $2-12$ & $\begin{array}{l}\text { Johnstone etal. (2008), Jennings etal. (2008), Lieberman et al. (2010), Johansson et al. (2010), } \\
\text { Takahashi etal. (2013), Luchsinger etal. (2013), Huijskens etal. (2014) }\end{array}$ \\
\hline $\begin{array}{l}\text { Exacerbation of idiopathic } \\
\text { pulmonary fibrosis }\end{array}$ & 5 & Wootton etal. (2011) \\
\hline Asymptomatic infection & 2 & Fry et al. (2011) \\
\hline
\end{tabular}

Table 2 | Respiratory symptoms.

\begin{tabular}{|c|c|}
\hline Upper respiratory symtoms & Lower respiratory symptoms \\
\hline Runny nose & Cough during the day \\
\hline Sneezing & Cough during the night \\
\hline Blocked or stuffy nose & Wheeze during the night \\
\hline Itchy, sore, or watery eyes & Difficulty breathing shortness of breath \\
\hline \multicolumn{2}{|l|}{ Sore throat } \\
\hline \multicolumn{2}{|l|}{ Hoarse voice } \\
\hline \multicolumn{2}{|l|}{ Fever of shivery } \\
\hline \multicolumn{2}{|l|}{ Headaches or face aches } \\
\hline Aches or pains elsewhere & \\
\hline
\end{tabular}

Cited and adapted from Johnston etal. (1995).

such as nucleic acid sequence-based amplification and RT-PCR is superior to those of culture methods (Loens et al., 2006).

\section{PATHOGENESIS OF HRV-ASSOCIATED ASTHMA EXACERBATIONS}

Experimental HRV infections have been shown to lead to a longlasting excessive airway narrowing in volunteer subjects with asthma (Cheung et al., 1995; Grunberg et al., 1999). Of note, rhinovirus, unlike influenza and other viruses, causes minimal cytotoxicity (Fraenkel et al., 1995), and the amount of epithelial damage does not correlate with the severity of the symptoms. HRV infection can cause additive or synergistic effects in exacerbation of asthma via the influx of additional inflammatory cells in the airways with preexisted inflammation, resulting in airway cholinergic hyperresponsiveness (Nagarkar et al., 2010), as an allergic response. The effects of HRV infection such as enhanced contractility of airway smooth muscle (ASM) cell and impaired relaxation to cholinergic or $\beta$-adrenaergic agonists are attributed solely to binding of the virus to its host receptor ICAM-1 on the ASM cell surface. This proasthmatic-like effect was recognized even in the situation of complete inhibition of viral replication in vitro, but not in the setting of pretreatment of ASM with neutralizing antibody directed against for
ICAM-1 (Grunstein et al., 2001). Thus, the HRV attachment to ICAM-1 itself can affects the contractility of ASM cells in the absence of any cytopathic effects, and Chun etal. (2013) reported that A 549 cells infected with HRV in vitro produced a higher value of IL-8 and RANTES than those of RSV or adenovirus. In addition, only the combination of HRV with Der f1 (house dust mites antigen) acted synergistically to induce IL-8 production. These findings are the reason why the HRV can be a major pathogen for acute exacerbation of asthma. We present a schema for pathogenesis in HRV associated asthma exacerbations (Figure 1), which requires the following steps, (1) HRV attachment to airway epithelial cells, (2) an innate immune response which leads to epithelial damage, (3) infection-related airway remodeling.

\section{ATTACHMENT TO AIRWAY EPITHELIAL CELLS}

When RT-PCR is used to either supplement or replace conventional culture techniques, viruses have been found in approximately one half to three quarters of adults experiencing an acute wheezing episode (Jackson and Johnston, 2010), and the majority $(59 \%)$ of viruses identified were HRVs (Nicholson etal., 1993). However, the evidence is weak, and mechanisms are poorly understood. Initially, HRV-A and -B attach to airway epithelial cells via ICAM-1 or LDLR (Kennedy et al., 2012). The receptor or receptors for the recently identified group HRV-C have yet to be clarified. HRV-infected BECs secrete a wide range of cytokines and chemokines such as IL-1, IL-6, CCL5/RANTES (regulated on activation, normal $\mathrm{T}$ cell expressed and secreted), CXCL8/IL-8, GM-CSF, and CXCL10/interferon-inducible protein 10 (IP-10; Jackson and Johnston, 2010; Proud, 2011), which induce neutrophilic, lymphocytic, and eosinophilic inflammation together with airway hyperresponsiveness and airway remodeling (Wark et al., 2002; Proud, 2011).

\section{THE INNATE IMMUNE RESPONSE}

Clearance of viral pathogens begins with interferon secretion, and the underproduction of these factors has been postulated to lead to viral-induced exacerbations. There are three types of interferons, based on the receptors they bind: type I (IFN- $\alpha / \beta)$, type II (IFN- $\gamma$ ), 


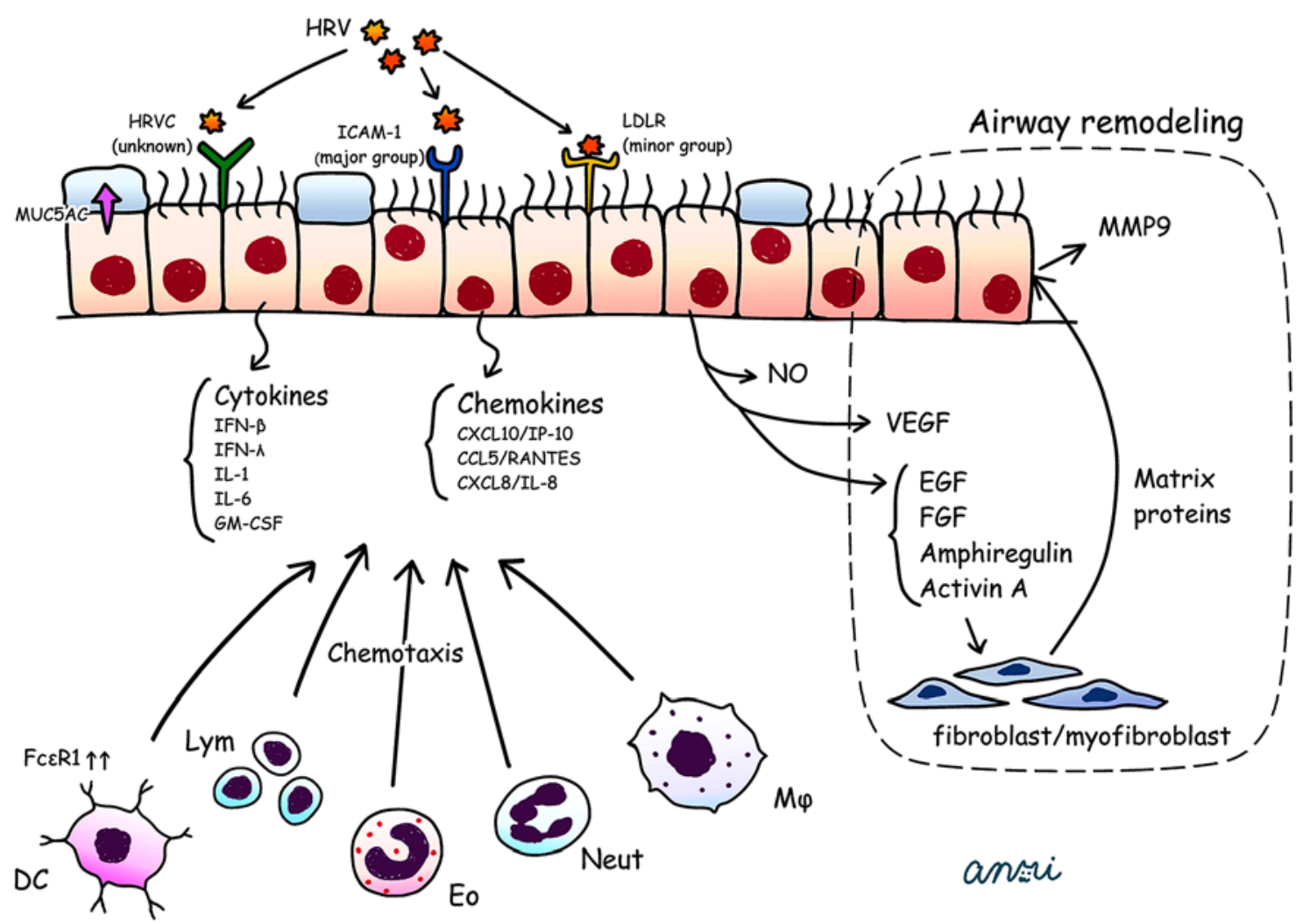

FIGURE 1 | HRV attaches to airway epithelial cells via ICAM-1, LDLR, and unknown receptors for HRV-C. HRV infected bronchial epithelial cells secrete a wide range of cytokines (IFN- $\beta$, IFN- $\lambda$, IL-1, IL-6, GM-CSF) and chemokines (CXCL10/IP-10, CCL5/RANTES, CXCL8/IL-8) together with NO, VEGF, and EGF, FGF, amphiregulin and activin $A$. These cytokines and chemokines attract various inflammatory cells such as DCs with upregulation of FceR1, Iym, Eo, Neut, and M $\phi$. The VEGF, EGF, FGF, amphiregulin and activin A promote the release of matrix proteins from fibroblasts/myofibroblasts, which enhance the production of MMP9 from airway epithelial cells. These phenomena could lead to airway remodeling (dotted area; i.e., thickening of the lamina reticularis). HRV infection induces secretion of MUC5AC, which impairs mucociliary clearance. DCs, dendritic cells; EGF, epidermal growth factor; Eo, eosinophil; FGF, fibroblast growth factor; GM-CSF, granulocyte macrophage colony-stimulating factor; ICAM-1, intercellular adhesion molecule 1; LDRL, low-density lipoprotein receptor; Lym, lymphocyte; MMP, matrix metalloproteinase; $M \phi$, macrophage; Neut, neutrophil; NO, nitric oxide synthase; RANTES, regulated on activation, normal T cell expressed and secreted; VEGF, vascular endothelial growth factor. and type III (IFN- $\lambda$ ). HRV infection induced epithelial expression of mRNA for both type I and type III IFNs, and it has been suggested that impaired epithelial production of IFN- $\beta$ and IFN$\lambda$ in asthmatic subjects may contribute to viral exacerbations of asthma (Wark et al., 2005; Contoli et al., 2006). Contoli et al. (2006) showed significant inverse correlations between ex vivo production of IFN- $\lambda$ and severity of symptoms, bronchoalveolar lavage viral load and airway inflammation, and a strong positive correlation with reductions in lung function during in vivo infection. Genome-wide association studies showed that single nucleotide polymorphisms involve in various diseases. Interferon- $\lambda$ polymorphisms may effect on the incidence of HRV infection (Russell et al., 2014).

Message etal. (2008) reported virus load in asthmatic subjects as being related to increased lower airway inflammation, and in turn increased lower airway inflammation being related to increased symptoms, reductions in lung function, and increases in bronchial hyperreactivity. These data suggest a causal role for HRV infection in the pathogenesis of asthma exacerbations.
Investigating virus-allergen interactions, Durrani et al. (2012) demonstrated that another mechanism that increased expression and cross-linking of the high-affinity IgE receptor, FceRI, on plasmacytoid dendritic cells is associated with reduced HRV-induced IFN- $\alpha$ and IFN- $\lambda 1$ secretion, and allergic asthmatic children have significantly reduced HRV-induced IFN- $\alpha$ and IFN- $\lambda 1$ production after cross-linking of FceRI.

Type 2, or inducible, nitric oxide synthase (iNOS) is the major NOS isoform found in epithelial cells and can generate substantial amounts of nitric oxide (NO). The NO molecules both inhibit the replication of HRV in airway epithelial cells, and suppresses HRV-induced cytokine production (Proud, 2005). Although the measurement of fractional NO concentration in exhaled breath (FENO) may be used to support the diagnosis of asthma (Dweik et al., 2011), however, increasing of FENO seems to be not always correlated with viral load during the period of HRV infection (Sanders et al., 2004).

Other factors such as allergy, allergen exposure, tobacco smoke, particulates, ozone, stress, and infections such as sinusitis commonly contribute to exacerbations of asthma. 


\section{HRV INFECTION AND AIRWAY REMODELING}

Grainge etal. (2011) reported that repeated bronchoconstriction in asthma promotes airway remodeling, and there is now clear evidence that airway remodeling begins in early childhood, and can be present even before clinical diagnosis of asthma is established (Pohunek et al., 2005). Increasing evidence regarding HRV-induced wheezing or exacerbation of asthma raises the possibility that HRV infections could contribute to the initiation and subsequent progression of airway remodeling, which involves multiple factors such as increased epithelial release of Mucin5AC (MU5AC), activin A, amphiregulin, matrix metalloproteinase 9 (MMP9), epidermal growth factor (EGF), fibroblast growth factor (FGF), and vascular endothelial growth factor (VEGF).

HRV infection upregulates production of MUC5AC from epithelial cells, which leads to airflow obstruction in asthma (Hewson et al., 2010). Activin A is a member of the TGF- $\beta$ superfamily and amphiregulin, a member of the EGF family, alters repair processes (Leigh et al., 2008). Both activin A and amphiregulin have been linked to subepithelial basement membrane thickening in asthma. MMP9 appears to have important roles in asthma exacerbation and airway remodeling (Sampsonas et al., 2007). Expression of VEGF and its receptors is increased in asthmatic subjects, and VEGF is the major proangiogenic activator in asthmatic airways (Feltis et al., 2006; Simcock et al., 2007).

\section{IMPACTS OF VIRAL INFECTION ON ASTHMA EXACERBATION: PRELIMINARY DATA FROM THE KYORIN COHORT STUDY}

Kuga et al. (2000) reported that $61.5 \%$ of adult asthmatic patients with common cold suffered an asthma attack, and common cold was significantly associated with acute exacerbations of asthma. They also stated that HRV infection might be important as the virus was detected by RT-PCR in throat gargles (Kuga etal., 2000). Virus-induced exacerbation of asthma is a critical issue for the general physician. However, among asthmatic patients with exacerbative status, distinguishing between those patients which have VRIs, and those who do not, is difficult. Furthermore, epidemiological data regarding adult asthma exacerbations have been sparsely reported. To investigate the prevalence of VRI in exacerbations of adult asthma in both hospitalized or not-hospitalized patients, characterization of clinical and radiological findings was performed. A prospective observational cohort study was conducted at Kyorin University Hospital, Tokyo, Japan from August 2012 to August 2013 (Kurai et al., 2013b). All patients with respiratory symptoms associated with exacerbation of asthma were included, and samples were collected by nasopharyngeal or oropharyngeal swab, and subjected to a PCR method to detect common respiratory viruses. The 44 patients who were enrolled consisted of hospitalized $(n=15)$ or not-hospitalized patients $(n=29$; Table 3$)$. In these two groups, the subject's backgrounds were similar for age, sex, smoking rates, and duration of illness, however, the measured value of $\mathrm{SpO}_{2}$ was significantly lower in hospitalized patients $(87 \pm 2.3 \%)$ than in non-hospitalized patients $(96.2 \pm 0.7 \%)$. The incidence of VRI was significantly higher in the former group $(46.7 \%, n=7)$ than in the latter group $(6.9 \%, n=2$; $p=0.002)$. In the latter group, influenza virus alone was detected in both patients. Furthermore, all hospitalized patients $(100 \%$, $n=15$ ) had wheezing or severe exacerbation based on the ATS (American Thoracic Society)/ERS (European Respiratory Society) statement (Reddel etal., 2009), whereas, among nonhospitalized patients, only nine patients $(31 \%)$ were considered as having a severe exacerbation $(p<0.001)$, and 10 patients (38.4\%) had wheezing $(p<0.001)$. These findings suggested that virus infection was certainly associated with the hypoxemia and / or wheezing which resulted in a severe or serious asthma attack, based on the Japanese guidelines (Ohta et al., 2011) or the ATS/ERS statement (Reddel et al., 2009). Previous studies using

Table 3 | Comparison of the clinical characteristics of hospitalized and non-hospitalized asthma attack patients.

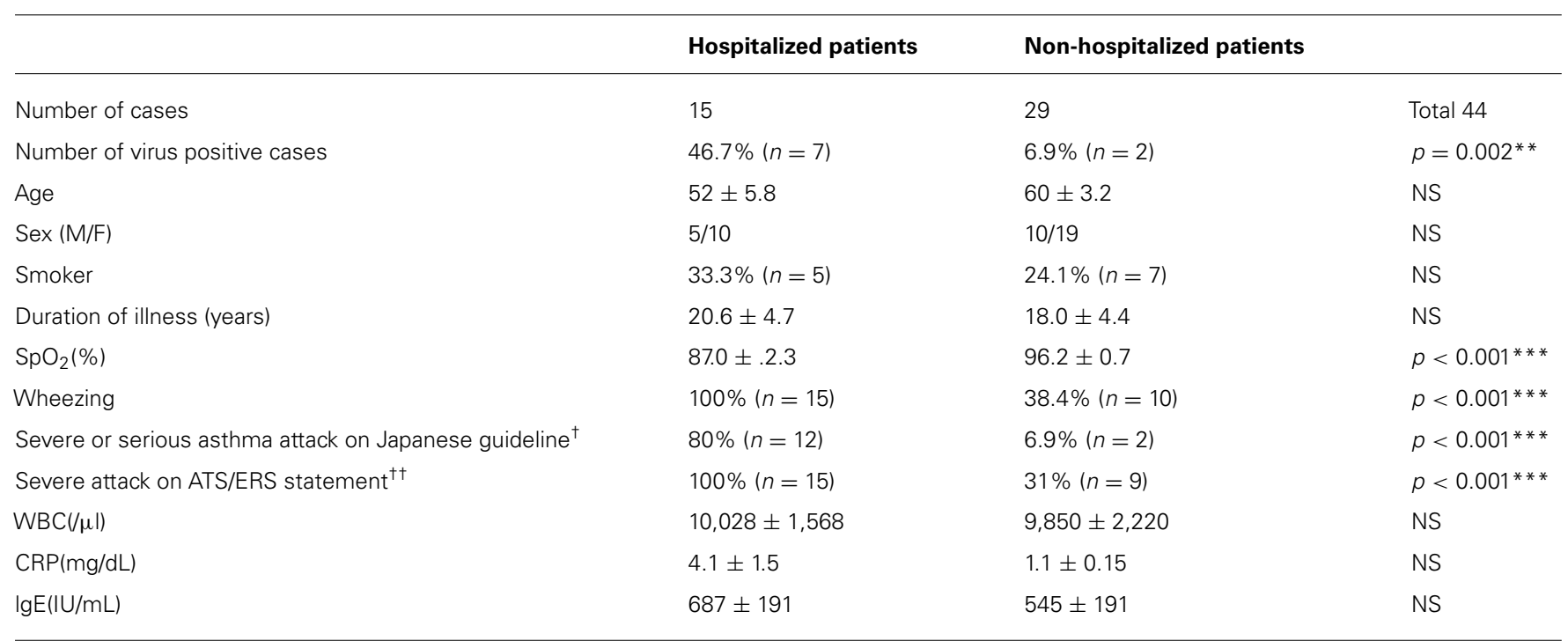

${ }^{\dagger}$ Defined by Ohta etal. (2011), ${ }^{\dagger \dagger}$ defined by Reddel et al. (2009). ${ }^{* *} p<0.01,{ }^{* * *} p<0.001$. All data are presented as (mean \pm SD). 
PCR-based viral diagnostics found that viral respiratory infections were detected in up to $85 \%$ of exacerbations of asthma in children and about $50 \%$ of exacerbations in adults (Nicholson et al., 1993; Johnston et al., 1995), which is similar to our results. Serum inflammatory or allergic markers are not different between the hospitalized and non-hospitalized patients (Table 3).

In hospitalized patients, the viruses identified were HRV $(n=5)$, HMPV $(n=1)$, and RSV $(n=1)$. At the time of admission, the virus-positive group $(n=7)$ had significant lower values of $\mathrm{SpO}_{2}(81.4 \pm 3.9 \%)$ than those of the virus-negative group $\left(n=8, \mathrm{SpO}_{2:} 91.8 \pm 1.3 \%, p<0.007\right)$, and for the patients whose data are available, the frequency of hypercapnea $\left(\mathrm{PaCO}_{2} \geqq 45\right.$ Torr) was significantly higher in the virus positive group $(66.7 \%$, $n=4)$ than in the virus negative group $(0 \% ; p=0.014$; Table 4$)$. The mechanisms for hypercapnea in virus infected individuals have not been elucidated. However, Cheung et al. (1995) reported that HRV infection causes long lasting excessive airway narrowing in response to methacholine in asthmatic subjects. We speculated that smooth muscle might have a role in exaggerated airway narrowing in virus positive asthmatic patients, as described by King et al. (1999).

Interestingly, the incidence of ground glass opacities (GGO) on high resolution computed tomography seemed to be higher for virus-positive hospitalized patients than for virus-negative patients, but it did not reach statistical significance. For example, Figure 2A shows a patchy GGO with thickening of interlobular septa in a 28-year-old woman who was admitted during an asthma attack induced by HRV-A. Figure 2B also shows GGO in a 62-year-old man with an asthma attack caused by HRV-C infection. These GGO in both patients could only be detected in HRCT, not in chest X-ray.
These results suggested that HRV was the major cause of virusinduced asthma, and was possibly involved in lower airway or lung parenchyma features, appearing as GGO. Viral infection significantly exaggerated the respiratory status (low $\mathrm{SpO}_{2}$ and hypercapnea) when compared to that of virus-negative asthma exacerbative patients at the time of admission. Indeed, in recent years, HRV has been recognized as a common cause of hospital admission, both as an agent of bronchopneumonia and through exacerbation of chronic pulmonary conditions, even in the elderly over 65 years of age (Pierangeli et al., 2011).

Curiously, after initiation of treatment with intravenous steroid, both the virus-positive and -negative groups had no significant difference in duration of respiratory failure, wheezing, days in hospital, and even in the time required for steroid treatment.

\section{TREATMENT}

No established treatment for prevention of HRV-induced asthma is available, and we describe the exploratory interventions as follows.

\section{INHALED CORTICOSTEROID}

Inhaled corticosteroid (ICS) is the main drug for regular asthma therapy. ICS treatment improved airway hyperresponsiveness in asthmatic patients experimentally challenged with HRV, however, ICS treatment did not reduce accumulation of inflammatory cells, except for eosinophils in bronchial epithelium (Grunberg et al., 2001). Double-stranded RNA (dsRNA), a viral product and a ligand for the Toll-like receptor-3 (TLR3), upregulates the expression of inflammatory chemokines in airway epithelial cells. Matsukura et al. (2013) reported that treatment of BEAS-2B cells with fluticasone propionate significantly and dose-dependently inhibited dsRNA-induced expression of CCL5, CXCL8, and CXCL10 protein

Table 4 | Clinical characterization of hospitalized patients with asthma attack based on the presence of virus infection.

\begin{tabular}{|c|c|c|c|}
\hline Number of hospitalized patients & 7 & 8 & Total 15 \\
\hline $\operatorname{Sex}(M / F)$ & $3 / 4$ & $3 / 6$ & NS \\
\hline Smoker & $28.6 \%(n=2)$ & $37.5 \%(n=3)$ & NS \\
\hline Wheezing & $100 \%(n=7)$ & $100 \%(n=8)$ & NS \\
\hline Severe or serious asthma attack on Japanese guideline $\dagger$ & $100 \%(n=7)$ & $62.5 \%(n=5)$ & NS \\
\hline Severe attack on ATS/ERS statement $\dagger \dagger$ & $100 \%(n=7)$ & $100 \%(n=8)$ & NS \\
\hline $\mathrm{PaCO}_{2} \geq 45$ Torr & $66.7 \%(4 / 6)$ & $0 \%(0 / 6)$ & $p=0.014^{*}$ \\
\hline Duration of steroid treatment (days) & $13.7 \pm 3.8$ & $12.9 \pm 3.5$ & NS \\
\hline Duration of hospital stays (days) & $7.3 \pm 2.0$ & $7.3 \pm 1.8$ & NS \\
\hline
\end{tabular}

${ }^{*} p<0.05,{ }^{* *} p<0.01$. All data are presented as (mean $\left.\pm S D\right)$. 

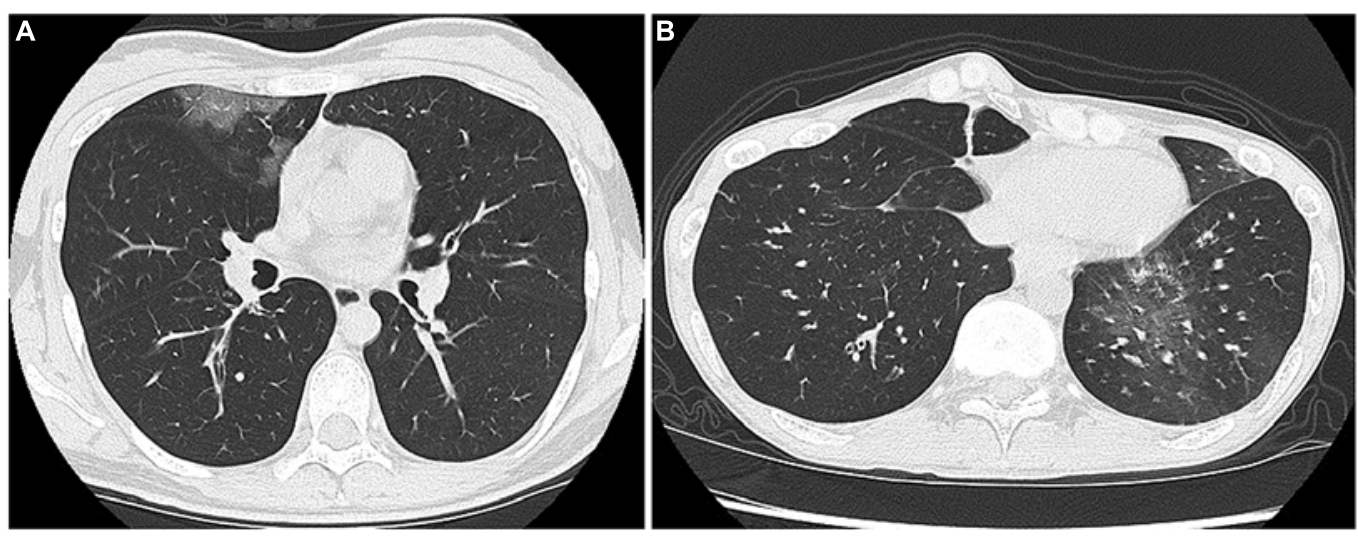

FIGURE 2 | (A) Shows a patchy GGO with thickening of interlobular septa in a 28-year-old woman who was admitted during an asthma attack induced by HRV-A. (B) Also shows GGO in a 62-year-old man with an asthma attack caused by HRV-C infection.

and mRNA. To confirm the effect on ssRNA, such as that of HRV, would need further studies.

\section{LEUKOTRIENE RECEPTOR ANTAGONIST}

Leukotriene receptor antagonist was prescribed in asthmatic patients with or without ICS. Montelukast treatment did not improve asthma control or cold symptom scores when HRV were experimentally inoculated into mild asthmatics, or healthy subjects (Kloepfer etal., 2011). It is uncertain whether leukotriene receptor antagonist treatment is effective in the reduction of asthma symptoms associated with HRV infection.

\section{ANTI-IgE THERAPY}

Zambrano etal. (2003) reported that high serum IgE levels in mildly asthmatic children with experimental HRV infection may be associated with enhanced lower respiratory symptoms and elevation of inflammatory markers, such as nasal eosinophil cationic protein and expired nitric oxide, than those of healthy subjects and/or low IgE asthmatic patients. The prevalence of asthma was closely associated with the serum IgE levels standardized for age and sex (Burrows et al., 1989), and airway hyperresponsiveness appears to be closely linked to the allergic diathesis, as reflected by the serum total IgE level (Sears et al., 1991). Omalizumab, an anti-IgE monoclonal antibody, was indicated in inadequately controlled moderate-to-severe persistent allergic asthma patients who were treated with high dose ICS. Durrani etal. (2012) showed that the IgE receptor Fc\&RI is inversely associated with IFN- $\alpha$ and IFN- $\lambda 1$ secretion when plasmacytoid dendritic cells derived from allergic asthmatic children were challenged with HRV. Omalizumab downregulates FceRI expression on dendritic cells (Prussin etal., 2003), which may reduce exacerbation of asthma associated with increased production of IFNs, through FceRI.

\section{ANTI-VIRAL TREATMENT}

No drugs are clinically used in HRV infection, although several drugs have been tried for treatment and prevention of HRV infection. These drugs are summarized in a review (Jacobs et al., 2013). IFNs had a potential protective role in viral induced asthma (Cakebread et al., 2011; Gaajetaan et al., 2013). Becker et al. (2013) showed that exogenous IFN- $\alpha$, IFN- $\beta$, IFN- $\lambda 1$, and IFN- $\lambda 2$ inhibited HRV replication in BECs from healthy donors.

\section{MACROLIDE THERAPY}

Macrolides are known to possess anti-inflammatory and immunomodulatory actions extending beyond their antibacterial activity in pulmonary inflammatory disorders (Takizawa et al., 1995; Min and Jang, 2012). Erythromycin inhibits HRV infection by reducing ICAM-1 expression on the surface of human tracheal epithelial cells, and modulates inflammation by suppressing the production of proinflammatory cytokines (Suzuki et al., 2002).

\section{OTHER AGENTS}

Yamaya et al. (2014) reported that the mucolytic drug ambroxol hydrochloride, antibiotic drug of levofloxacin (Yamaya etal., 2012b), and bronchodilators (Tiotropium, Tulobuterol, and Procaterol) for asthma or COPD (Yamaya et al., 2011, 2012a, 2013) may have a beneficial effect in HRV infection, by inhibiting HRV replication and partly reducing ICAM-1 expression and acidic endosome production, via the inhibition of NF-kappaB activation (Yamaya, 2012).

\section{SUMMARY}

We reviewed the previous reports regarding HRV-induced asthma exacerbations, together with our results from an institutional prospective study. HRV is a major pathogen for asthma exacerbations, and certainly associated with more serious clinical conditions such as hypoxemia or hypercapnea in hospitalized patients. Further accumulation of evidence of virus-induced asthma for multidisciplinary assessment would be helpful for physicians in recognizing the condition or understanding the pathogenic mechanisms.

\section{REFERENCES}

Andries, K., Dewindt, B., Snoeks, J., Wouters, L., Moereels, H., Lewi, P. J., et al. (1990). Two groups of rhinoviruses revealed by a panel of antiviral compounds 
present sequence divergence and differential pathogenicity. J. Virol. 64, 11171123.

Arakawa, M., Okamoto-Nakagawa, R., Toda, S., Tsukagoshi, H., Kobayashi, M., Ryo, A., et al. (2012). Molecular epidemiological study of human rhinovirus species A, $\mathrm{B}$ and $\mathrm{C}$ from patients with acute respiratory illnesses in Japan. J. Med. Microbiol. 61, 410-419. doi: 10.1099/jmm.0.035006-0

Arruda, E., Pitkaranta, A., Witek, T. J. Jr., Doyle, C. A., and Hayden, F. G. (1997). Frequency and natural history of rhinovirus infections in adults during autumn. J. Clin. Microbiol. 35, 2864-2868.

Atmar, R. L., Guy, E., Guntupalli, K. K., Zimmerman, J. L., Bandi, V. D., Baxter, B. D., et al. (1998). Respiratory tract viral infections in inner-city asthmatic adults. Arch. Intern. Med. 158, 2453-2459. doi: 10.1001/archinte.158.22.2453

Bartlett, N. W., Walton, R. P., Edwards, M. R., Aniscenko, J., Caramori, G., Zhu, J., et al. (2008). Mouse models of rhinovirus-induced disease and exacerbation of allergic airway inflammation. Nat. Med. 14, 199-204. doi: 10.1038/ nm1713

Becker, T. M., Durrani, S. R., Bochkov, Y. A., Devries, M. K., Rajamanickam, V., and Jackson, D. J. (2013). Effect of exogenous interferons on rhinovirus replication and airway inflammatory responses. Ann. Allergy Asthma Immunol. 111, 397-401. doi: 10.1016/j.anai.2013.07.029

Beckham, J. D., Cadena, A., Lin, J., Piedra, P. A., Glezen, W. P., Greenberg, S. B., et al. (2005). Respiratory viral infections in patients with chronic, obstructive pulmonary disease. J. Infect. 50, 322-330. doi: 10.1016/j.jinf.2004. 07.011

Bochkov, Y. A., Hanson, K. M., Keles, S., Brockman-Schneider, R. A., Jarjour, N. N., and Gern, J. E. (2010). Rhinovirus-induced modulation of gene expression in bronchial epithelial cells from subjects with asthma. Mucosal Immunol. 3, 69-80. doi: 10.1038/mi.2009.109

Burrows, B., Martinez, F. D., Halonen, M., Barbee, R. A., and Cline, M. G. (1989). Association of asthma with serum IgE levels and skin-test reactivity to allergens. N. Engl. J. Med. 320, 271-277. doi: 10.1056/NEJM198902023200502

Cakebread, J. A., Xu, Y., Grainge, C., Kehagia, V., Howarth, P. H., Holgate, S. T., et al. (2011). Exogenous IFN-beta has antiviral and anti-inflammatory properties in primary bronchial epithelial cells from asthmatic subjects exposed to rhinovirus. J. Allergy Clin. Immunol. 127, 1148e9-1154e9. doi: 10.1016/j.jaci.2011. 01.023

Cheung, D., Dick, E. C., Timmers, M. C., De Klerk, E. P., Spaan, W. J., and Sterk, P. J. (1995). Rhinovirus inhalation causes long-lasting excessive airway narrowing in response to methacholine in asthmatic subjects in vivo. Am. J. Respir. Crit. Care Med. 152, 1490-1496. doi: 10.1164/ajrccm.152.5.7582282

Chun, Y. H., Park, J. Y., Lee, H., Kim, H. S., Won, S., Joe, H. J., et al. (2013). Rhinovirus-infected epithelial cells produce more IL-8 and rantes compared with other respiratory viruses. Allergy Asthma Immunol. Res. 5, 216-223. doi: 10.4168/aair.2013.5.4.216

Contoli, M., Message, S. D., Laza-Stanca, V., Edwards, M. R., Wark, P. A., Bartlett, N. W., et al. (2006). Role of deficient type III interferon-lambda production in asthma exacerbations. Nat. Med. 12, 1023-1026. doi: 10.1038/ nm1462

Corne, J. M., Marshall, C., Smith, S., Schreiber, J., Sanderson, G., Holgate, S. T., et al. (2002). Frequency, severity, and duration of rhinovirus infections in asthmatic and non-asthmatic individuals: a longitudinal cohort study. Lancet 359, 831-834. doi: 10.1016/S0140-6736(02)07953-9

DeMore, J. P., Weisshaar, E. H., Vrtis, R. F., Swenson, C. A., Evans, M. D., Morin, A., et al. (2009). Similar colds in subjects with allergic asthma and nonatopic subjects after inoculation with rhinovirus-16. J. Allergy Clin. Immunol. 124, 245-252. doi: 10.1016/j.jaci.2009.05.030

Dimopoulos, G., Lerikou, M., Tsiodras, S., Chranioti, A., Perros, E., Anagnostopoulou, U., et al. (2012). Viral epidemiology of acute exacerbations of chronic obstructive pulmonary disease. Pulm. Pharmacol. Ther. 25, 12-18. doi: 10.1016/j.pupt.2011.08.004

Durrani, S. R., Montville, D. J., Pratt, A. S., Sahu, S., Devries, M. K., Rajamanickam, V., et al. (2012). Innate immune responses to rhinovirus are reduced by the highaffinity IgE receptor in allergic asthmatic children. J. Allergy Clin. Immunol. 130, 489-495. doi: 10.1016/j.jaci.2012.05.023

Dweik, R. A., Boggs, P. B., Erzurum, S. C., Irvin, C. G., Leigh, M. W., Lundberg, J. O., et al. (2011). An official ATS clinical practice guideline: interpretation of exhaled nitric oxide levels (FENO) for clinical applications. Am. J. Respir. Crit. Care Med. 184, 602-615. doi: 10.1164/rccm.9120-11ST
Fashner, J., Ericson, K., and Werner, S. (2012). Treatment of the common cold in children and adults. Am. Fam. Phys. 86, 153-159.

Feltis, B. N., Wignarajah, D., Zheng, L., Ward, C., Reid, D., Harding, R., et al. (2006). Increased vascular endothelial growth factor and receptors: relationship to angiogenesis in asthma. Am. J. Respir. Crit. Care Med. 173, 1201-1207. doi: 10.1164/rccm.200507-1105OC

Fraenkel, D. J., Bardin, P. G., Sanderson, G., Lampe, F., Johnston, S. L., and Holgate, S. T. (1995). Lower airways inflammation during rhinovirus colds in normal and in asthmatic subjects. Am. J. Respir. Crit. Care Med. 151, 879-886.

Fry, A. M., Lu, X., Olsen, S. J., Chittaganpitch, M., Sawatwong, P., Chantra, S., et al. (2011). Human rhinovirus infections in rural Thailand: epidemiological evidence for rhinovirus as both pathogen and bystander. PLoS ONE 6:e17780. doi: 10.1371/journal.pone.0017780

Fujitsuka, A., Tsukagoshi, H., Arakawa, M., Goto-Sugai, K., Ryo, A., Okayama, Y., et al. (2011). A molecular epidemiological study of respiratory viruses detected in Japanese children with acute wheezing illness. BMC Infect. Dis. 11:168. doi: 10.1186/1471-2334-11-168

Gaajetaan, G. R., Geelen, T. H., Vernooy, J. H., Dentener, M. A., Reynaert, N. L., Rohde, G. G., et al. (2013). Interferon-beta induces a long-lasting antiviral state in human respiratory epithelial cells. J. Infect. 66, 163-169. doi: 10.1016/j.jinf.2012.11.008

Grainge, C. L., Lau, L. C., Ward, J. A., Dulay, V., Lahiff, G., Wilson, S., et al. (2011). Effect of bronchoconstriction on airway remodeling in asthma. N. Engl. J. Med. 364, 2006-2015. doi: 10.1056/NEJMoa1014350

Grunberg, K., Sharon, R. F., Sont, J. K., In 't Veen, J. C., Van Schadewijk, W. A., De Klerk, E. P., et al. (2001). Rhinovirus-induced airway inflammation in asthma: effect of treatment with inhaled corticosteroids before and during experimental infection. Am. J. Respir. Crit. Care Med. 164, 1816-1822.

Grunberg, K., Timmers, M. C., De Klerk, E. P., Dick, E. C., and Sterk, P. J. (1999). Experimental rhinovirus 16 infection causes variable airway obstruction in subjects with atopic asthma. Am. J. Respir. Crit. Care Med. 160, 1375-1380. doi: 10.1164/ajrccm.160.4.9810083

Grunstein, M. M., Hakonarson, H., Whelan, R., Yu, Z., Grunstein, J. S., and Chuang, S. (2001). Rhinovirus elicits proasthmatic changes in airway responsiveness independently of viral infection. J. Allergy Clin. Immunol. 108, 997-1004. doi: 10.1067/mai.2001.120276

Gwaltney, J. M. Jr., Hendley, J. O., Simon, G., and Jordan, W. S. Jr. (1967). Rhinovirus infections in an industrial population. II. Characteristics of illness and antibody response. JAMA 202, 494-500. doi: 10.1001/jama.1967.03130190100014

Hewson, C. A., Haas, J. J., Bartlett, N. W., Message, S. D., Laza-Stanca, V., Kebadze, T., et al. (2010). Rhinovirus induces Muc5ac in a human infection model and in vitro via NF-kappaB and EGFR pathways. Eur. Respir. J. 36, 1425-1435. doi: 10.1183/09031936.00026910

Hsiao, C. J., Cherry, D. K., Beatty, P. C., and Rechtsteiner, E. A. (2010). National ambulatory medical care survey: 2007 summary. Natl. Health Stat. Report 1:32.

Huijskens, E. G., Koopmans, M., Palmen, F. M., Van Erkel, A. J., Mulder, P. G., and Rossen, J. W. (2014). The value of signs and symptoms in differentiating between bacterial, viral and mixed aetiology in patients with communityacquired pneumonia. J. Med. Microbiol. 63, 441-452. doi: 10.1099/jmm.0.06 7108-0

Hutchinson, A. F., Ghimire, A. K., Thompson, M. A., Black, J. F., Brand, C. A., Lowe, A. J., et al. (2007). A community-based, time-matched, case-control study of respiratory viruses and exacerbations of COPD. Respir. Med. 101, 2472-2481. doi: 10.1016/j.rmed.2007.07.015

Jackson, D. J., and Johnston, S. L. (2010). The role of viruses in acute exacerbations of asthma. J. Allergy Clin. Immunol. 125, 1178-1187. doi: 10.1016/j.jaci.2010.04.021

Jacobs, S. E., Lamson, D. M., St George, K., and Walsh, T. J. (2013). Human rhinoviruses. Clin. Microbiol. Rev. 26, 135-162. doi: 10.1128/CMR.00077-12

Jennings, L. C., Anderson, T. P., Beynon, K. A., Chua, A., Laing, R. T., Werno, A. M., et al. (2008). Incidence and characteristics of viral community-acquired pneumonia in adults. Thorax 63, 42-48. doi: 10.1136/thx.2006.075077

Johansson, N., Kalin, M., Tiveljung-Lindell, A., Giske, C. G., and Hedlund, J. (2010). Etiology of community-acquired pneumonia: increased microbiological yield with new diagnostic methods. Clin. Infect. Dis. 50, 202-209. doi: 10.1086/648678 Johnstone, J., Majumdar, S. R., Fox, J. D., and Marrie, T. J. (2008). Viral infection in adults hospitalized with community-acquired pneumonia: prevalence, pathogens, and presentation. Chest 134, 1141-1148. doi: 10.1378/chest. 08-0888 
Johnston, S. L., Pattemore, P. K., Sanderson, G., Smith, S., Campbell, M. J., Josephs, L. K., et al. (1996). The relationship between upper respiratory infections and hospital admissions for asthma: a time-trend analysis. Am. J. Respir. Crit. Care Med. 154, 654-660. doi: 10.1164/ajrccm.154.3.8810601

Johnston, S. L., Pattemore, P. K., Sanderson, G., Smith, S., Lampe, F., Josephs, L., et al. (1995). Community study of role of viral infections in exacerbations of asthma in 9-11 year old children. BMJ 310, 1225-1229. doi: 10.1136/bmj.310.6989.1225

Kennedy, J. L., Turner, R. B., Braciale, T., Heymann, P. W., and Borish, L. (2012). Pathogenesis of rhinovirus infection. Curr. Opin. Virol. 2, 287-293. doi: 10.1016/j.coviro.2012.03.008

Kherad, O., Kaiser, L., Bridevaux, P. O., Sarasin, F., Thomas, Y., Janssens, J. P., et al. (2010). Upper-respiratory viral infection, biomarkers, and COPD exacerbations. Chest 138, 896-904. doi: 10.1378/chest.09-2225

King, G. G., Pare, P. D., and Seow, C. Y. (1999). The mechanics of exaggerated airway narrowing in asthma: the role of smooth muscle. Respir. Physiol. 118, 1-13. doi: 10.1016/S0034-5687(99)00076-6

Kiyota, N., Kobayashi, M., Tsukagoshi, H., Ryo, A., Harada, S., Kusaka, T., et al. (2014). Genetic analysis of human rhinovirus species A to C detected in patients with acute respiratory infection in Kumamoto prefecture, Japan 2011-2012. Infect. Genet. Evol. 21, 90-102. doi: 10.1016/j.meegid.2013.10.024

Kiyota, N., Kushibuchi, I., Kobayashi, M., Tsukagoshi, H., Ryo, A., Nishimura, K., et al. (2013). Genetic analysis of the VP4/VP2 coding region in human rhinovirus species $\mathrm{C}$ in patients with acute respiratory infection in Japan. J. Med. Microbiol. 62, 610-617. doi: 10.1099/jmm.0.049072-0

Kloepfer, K. M., Demore, J. P., Vrtis, R. F., Swenson, C. A., Gaworski, K. L., Bork, J. A., et al. (2011). Effects of montelukast on patients with asthma after experimental inoculation with human rhinovirus 16. Ann. Allergy Asthma Immunol. 106, 252 257. doi: 10.1016/j.anai.2010.11.021

Ko, F. W., Ip, M., Chan, P. K., Chan, M. C., To, K. W., Ng, S. S., et al. (2007). Viral etiology of acute exacerbations of COPD in Hong Kong. Chest 132, 900-908. doi: 10.1378/chest.07-0530

Kuga, H., Hoshiyama, Y., Kokubu, F., Imai, T., Tokunaga, H., Matsukura, S., et al. (2000). The correlation between the exacerbation of bronchial asthma and picornavirus (human rhino virus) infection in throat gargles by RT-PCR. Arerugi 49, 358-364.

Kurai, D., Saraya, T., Ishii, H., and Takizawa, H. (2013a). Virusinduced exacerbations in asthma and COPD. Front. Microbiol. 4:293. doi: 10.3389/fmicb.2013.00293

Kurai, D., Saraya, T., Ishii, H., Wada, H., Tsukagoshi, H., Takizawa, H., et al. (2013b). Respiratory viral infection in admitted adult patients. Respirology 18, 1-81.

Leigh, R., Oyelusi, W., Wiehler, S., Koetzler, R., Zaheer, R. S., Newton, R., et al. (2008). Human rhinovirus infection enhances airway epithelial cell production of growth factors involved in airway remodeling. J. Allergy Clin. Immunol. 121, 1238e4-1245e4. doi: 10.1016/j.jaci.2008.01.067

Lieberman, D., Lieberman, D., Shimoni, A., Keren-Naus, A., Steinberg, R., and Shemer-Avni, Y. (2009). Identification of respiratory viruses in adults: nasopharyngeal versus oropharyngeal sampling. J. Clin. Microbiol. 47, 3439-3443. doi: 10.1128/JCM.00886-09

Lieberman, D., Shimoni, A., Shemer-Avni, Y., Keren-Naos, A., Shtainberg, R., and Lieberman, D. (2010). Respiratory viruses in adults with community-acquired pneumonia. Chest 138, 811-816. doi: 10.1378/chest.09-2717

Linsuwanon, P., Payungporn, S., Samransamruajkit, R., Posuwan, N., Makkoch, J., Theanboonlers, A., et al. (2009). High prevalence of human rhinovirus C infection in Thai children with acute lower respiratory tract disease. J. Infect. 59, 115-121. doi: 10.1016/j.jinf.2009.05.009

Loens, K., Goossens, H., De Laat, C., Foolen, H., Oudshoorn, P., Pattyn, S., et al. (2006). Detection of rhinoviruses by tissue culture and two independen amplification techniques, nucleic acid sequence-based amplification and reverse transcription-PCR, in children with acute respiratory infections during a winter season. J. Clin. Microbiol. 44, 166-171. doi: 10.1128/JCM.44.1.166-171.2006

Lopez-Souza, N., Favoreto, S., Wong, H., Ward, T., Yagi, S., Schnurr, D., et al. (2009). In vitro susceptibility to rhinovirus infection is greater for bronchial than for nasal airway epithelial cells in human subjects. J. Allergy Clin. Immunol. 123, 1384e2-1390e2. doi: 10.1016/j.jaci.2009.03.010

Luchsinger, V., Ruiz, M., Zunino, E., Martinez, M. A., Machado, C., Piedra, P. A., et al. (2013). Community-acquired pneumonia in Chile: the clinical relevance in the detection of viruses and atypical bacteria. Thorax 68, 1000-1006. doi: 10.1136/thoraxinl-2013-203551
Makela, M. J., Puhakka, T., Ruuskanen, O., Leinonen, M., Saikku, P., Kimpimaki, M., et al. (1998). Viruses and bacteria in the etiology of the common cold. J. Clin. Microbiol. 36, 539-542.

Matsukura, S., Kurokawa, M., Homma, T., Watanabe, S., Suzuki, S., Ieki, K., et al. (2013). Basic research on virus-induced asthma exacerbation: inhibition of inflammatory chemokine expression by fluticasone propionate. Int. Arch. Allergy Immunol. 161(Suppl. 2), 84-92. doi: 10.1159/000350455

McFadden, E. R. Jr., Pichurko, B. M., Bowman, H. F., Ingenito, E., Burns, S., Dowling, N., et al. (1985). Thermal mapping of the airways in humans. J. Appl. Physiol. 58, 564-570.

McManus, T. E., Marley, A. M., Baxter, N., Christie, S. N., O’Neill, H. J., Elborn, J. S., et al. (2008). Respiratory viral infection in exacerbations of COPD. Respir. Med. 102, 1575-1580. doi: 10.1016/j.rmed.2008.06.006

Message, S. D., Laza-Stanca, V., Mallia, P., Parker, H. L., Zhu, J., Kebadze, T., et al. (2008). Rhinovirus-induced lower respiratory illness is increased in asthma and related to virus load and Th1/2 cytokine and IL-10 production. Proc. Natl. Acad. Sci. U.S.A. 105, 13562-13567. doi: 10.1073/pnas.0804181105

Min, J. Y., and Jang, Y. J. (2012). Macrolide therapy in respiratory viral infections. Mediators Inflamm. 2012, 649570. doi: 10.1155/2012/649570

Nagarkar, D. R., Bowman, E. R., Schneider, D., Wang, Q., Shim, J., Zhao, Y., et al. (2010). Rhinovirus infection of allergen-sensitized and -challenged mice induces eotaxin release from functionally polarized macrophages. J. Immunol. 185, 2525-2535. doi: 10.4049/jimmunol.1000286

Nicholson, K. G., Kent, J., and Ireland, D. C. (1993). Respiratory viruses and exacerbations of asthma in adults. BMJ 307, 982-986. doi: 10.1136/bmj.307.6910.982

Ohta, K., Yamaguchi, M., Akiyama, K., Adachi, M., Ichinose, M., Takahashi, K., et al. (2011). Japanese guideline for adult asthma. Allergol. Int. 60, 115-145. doi: 10.2332/allergolint.11-RAI-0327

Papi, A., Bellettato, C. M., Braccioni, F., Romagnoli, M., Casolari, P., Caramori, G., et al. (2006). Infections and airway inflammation in chronic obstructive pulmonary disease severe exacerbations. Am. J. Respir. Crit. Care Med. 173, 1114-1121. doi: 10.1164/rccm.200506-859OC

Perotin, J. M., Dury, S., Renois, F., Deslee, G., Wolak, A., Duval, V., et al. (2013). Detection of multiple viral and bacterial infections in acute exacerbation of chronic obstructive pulmonary disease: a pilot prospective study. J. Med. Virol. 85, 866-873. doi: 10.1002/jmv.23495

Pierangeli, A., Scagnolari, C., Selvaggi, C., Verzaro, S., Spina, M. T., Bresciani, E., et al. (2011). Rhinovirus frequently detected in elderly adults attending an emergency department. J. Med. Virol. 83, 2043-2047. doi: 10.1002/jmv.22205

Pohunek, P., Warner, J. O., Turzikova, J., Kudrmann, J., and Roche, W. R. (2005). Markers of eosinophilic inflammation and tissue re-modelling in children before clinically diagnosed bronchial asthma. Pediatr. Allergy Immunol. 16, 43-51. doi: 10.1111/j.1399-3038.2005.00239.x

Proud, D. (2005). Nitric oxide and the common cold. Curr. Opin. Allergy Clin. Immunol. 5, 37-42. doi: 10.1097/00130832-200502000-00008

Proud, D. (2011). Role of rhinovirus infections in asthma. Asian Pac. J. Allergy Immunol. 29, 201-208.

Prussin, C., Griffith, D. T., Boesel, K. M., Lin, H., Foster, B., and Casale, T. B. (2003). Omalizumab treatment downregulates dendritic cell Fcepsilonri expression. J. Allergy Clin. Immunol. 112, 1147-1154. doi: 10.1016/j.jaci.2003. 10.003

Reddel, H. K., Taylor, D. R., Bateman, E. D., Boulet, L. P., Boushey, H. A., Busse, W. W., et al. (2009). An official American Thoracic Society/European Respiratory Society statement: asthma control and exacerbations: standardizing endpoints for clinical asthma trials and clinical practice. Am. J. Respir. Crit. Care Med. 180, 59-99. doi: 10.1164/rccm.200801-060ST

Rohde, G., Wiethege, A., Borg, I., Kauth, M., Bauer, T. T., Gillissen, A., et al. (2003). Respiratory viruses in exacerbations of chronic obstructive pulmonary disease requiring hospitalisation: a case-control study. Thorax 58, 37-42. doi: 10.1136/thorax.58.1.37

Rotbart, H. A., and Hayden, F. G. (2000). Picornavirus infections: a primer for the practitioner. Arch. Fam. Med. 9, 913-920. doi: 10.1001/archfami.9.9.913

Russell, C. D., Griffiths, S. J., and Haas, J. (2014). Interferon lambda genetic polymorphisms and viral infection: the tip of the iceberg? DNA Cell Biol. 33, 60-63. doi: 10.1089/dna.2013.2261

Sampsonas, F., Kaparianos, A., Lykouras, D., Karkoulias, K., and Spiropoulos, K. (2007). DNA sequence variations of metalloproteinases: their role in asthma and Copd. Postgrad. Med. J. 83, 244-250. doi: 10.1136/pgmj.2006.052100 
Sanders, S. P., Proud, D., Permutt, S., Siekierski, E. S., Yachechko, R., and Liu, M. C. (2004). Role of nasal nitric oxide in the resolution of experimental rhinovirus infection. J. Allergy Clin. Immunol. 113, 697-702. doi: 10.1016/j.jaci.2004. 01.755

Sears, M. R., Burrows, B., Flannery, E. M., Herbison, G. P., Hewitt, C. J., and Holdaway, M. D. (1991). Relation between airway responsiveness and serum IgE in children with asthma and in apparently normal children. N. Engl. J. Med. 325, 1067-1071. doi: 10.1056/NEJM199110103251504

Seemungal, T., Harper-Owen, R., Bhowmik, A., Moric, I., Sanderson, G., Message, S., et al. (2001). Respiratory viruses, symptoms, and inflammatory markers in acute exacerbations and stable chronic obstructive pulmonary disease. Am. J. Respir. Crit. Care Med. 164, 1618-1623. doi: 10.1164/ajrccm.164.9.2105011

Simcock, D. E., Kanabar, V., Clarke, G. W., O’Connor, B. J., Lee, T. H., and Hirst, S. J. (2007). Proangiogenic activity in bronchoalveolar lavage fluid from patients with asthma. Am. J. Respir. Crit. Care Med. 176, 146-153. doi: 10.1164/rccm.200701042OC

Simmonds, P., McIntyre, C., Savolainen-Kopra, C., Tapparel, C., MacKay, I. M., and Hovi, T. (2010). Proposals for the classification of human rhinovirus species C into genotypically assigned types. J. Gen. Virol. 91, 2409-2419. doi 10.1099/vir.0.023994-0

Smuts, H. E., Workman, L. J., and Zar, H. J. (2011). Human rhinovirus infection in young African children with acute wheezing. BMC Infect. Dis. 11:65. doi: 10.1186/1471-2334-11-65

Suzuki, T., Yamaya, M., Sekizawa, K., Hosoda, M., Yamada, N., Ishizuka, S., et al. (2002). Erythromycin inhibits rhinovirus infection in cultured human tracheal epithelial cells. Am. J. Respir. Crit. Care Med. 165, 1113-1118. doi 10.1164/ajrccm.165.8.2103094

Sykes, A., MacIntyre, J., Edwards, M. R., Del Rosario, A., Haas, J., Gielen, V., et al. (2014). Rhinovirus-induced interferon production is not deficient in well controlled asthma. Thorax 69, 240-246. doi: 10.1136/thoraxjnl-2012-202909

Takahashi, K., Suzuki, M., Minh Le, N., Anh, N. H., Huong, L. T., Son, T. V., et al. (2013). The incidence and aetiology of hospitalised community-acquired pneumonia among Vietnamese adults: a prospective surveillance in Central Vietnam. BMC Infect. Dis. 13:296. doi: 10.1186/1471-2334-13-296

Takizawa, H., Desaki, M., Ohtoshi, T., Kikutani, T., Okazaki, H., Sato, M., et al. (1995). Erythromycin suppresses interleukin 6 expression by human bronchia epithelial cells: a potential mechanism of its anti-inflammatory action. Biochem. Biophys. Res. Commun. 210, 781-786. doi: 10.1006/bbrc.1995.1727

Tan, W. C., Xiang, X., Qiu, D., Ng, T. P., Lam, S. F., and Hegele, R. G. (2003). Epidemiology of respiratory viruses in patients hospitalized with near-fatal asthma, acute exacerbations of asthma, or chronic obstructive pulmonary disease. Am. J. Med. 115, 272-277. doi: 10.1016/S0002-9343(03) 00353-X

Tsukagoshi, H., Ishioka, T., Noda, M., Kozawa, K., and Kimura, H. (2013). Molecular epidemiology of respiratory viruses in virus-induced asthma. Front. Microbiol. 4:278. doi: 10.3389/fmicb.2013.00278

Turner, R. B., and Couch, R. B. (2007). "Rhinovirus," in Fields Virology, 5th edn, eds D. M. Knipe, P. M. Howley, D. E. Griffin, R. A. Lamb, M. A. Martin, B. Roizman, and S. E. Straus (Philadelphia: Lippincott Williams and Wilkins), 895-909.

Tyrrell, D. A., Cohen, S., and Schlarb, J. E. (1993). Signs and symptoms in common colds. Epidemiol. Infect. 111, 143-156. doi: 10.1017/S09502688000 56764

van Gageldonk-Lafeber, A. B., Heijnen, M. L., Bartelds, A. I., Peters, M. F., Van Der Plas, S. M., and Wilbrink, B. (2005). A case-control study of acute respiratory tract infection in general practice patients in The Netherlands. Clin. Infect. Dis. 41, 490-497. doi: 10.1086/431982
Wark, P. A., Johnston, S. L., Bucchieri, F., Powell, R., Puddicombe, S., LazaStanca, V., et al. (2005). Asthmatic bronchial epithelial cells have a deficient innate immune response to infection with rhinovirus. J. Exp. Med. 201, 937-947. doi: 10.1084/jem.20041901

Wark, P. A., Johnston, S. L., Moric, I., Simpson, J. L., Hensley, M. J., and Gibson, P. G. (2002). Neutrophil degranulation and cell lysis is associated with clinical severity in virus-induced asthma. Eur. Respir. J. 19, 68-75. doi: 10.1183/09031936.02.00226302

Watanabe, A., Carraro, E., Kamikawa, J., Leal, E., Granato, C., and Bellei, N. (2010). Rhinovirus species and their clinical presentation among different risk groups of non-hospitalized patients. J. Med. Virol. 82, 2110-2115. doi: 10.1002/jmv.21914

Wootton, S. C., Kim, D. S., Kondoh, Y., Chen, E., Lee, J. S., Song, J. W., et al. (2011). Viral infection in acute exacerbation of idiopathic pulmonary fibrosis. Am. J. Respir. Crit. Care Med. 183, 1698-1702. doi: 10.1164/rccm.201010-1752OC

Yamaya, M. (2012). Virus infection-induced bronchial asthma exacerbation. Pulm. Med. 2012, 834826. doi: 10.1155/2012/834826

Yamaya, M., Nishimura, H., Hatachi, Y., Yasuda, H., Deng, X., Sasaki, T., et al. (2012a). Inhibitory effects of tiotropium on rhinovirus infection in human airway epithelial cells. Eur. Respir. J. 40, 122-132. doi: 10.1183/09031936.00065111

Yamaya, M., Nishimura, H., Hatachi, Y., Yasuda, H., Deng, X., Sasaki, T., et al. (2012b). Levofloxacin inhibits rhinovirus infection in primary cultures of human tracheal epithelial cells. Antimicrob. Agents Chemother. 56, 4052-4061. doi: 10.1128/AAC.00259-12

Yamaya, M., Nishimura, H., Hatachi, Y., Yoshida, M., Fujiwara, H., Asada, M., et al. (2011). Procaterol inhibits rhinovirus infection in primary cultures of human tracheal epithelial cells. Eur. J. Pharmacol. 650, 431-444. doi: 10.1016/j.ejphar.2010.09.056

Yamaya, M., Nishimura, H., Nadine, L., Kubo, H., and Ryoichi, N. (2013). Tulobuterol inhibits rhinovirus infection in primary cultures of human tracheal epithelial cells. Physiol. Rep. 1, e00041. doi: 10.1002/phy2.41

Yamaya, M., Nishimura, H., Nadine, L. K., Ota, C., Kubo, H., and Nagatomi, R. (2014). Ambroxol inhibits rhinovirus infection in primary cultures of human tracheal epithelial cells. Arch. Pharm. Res. 37, 520-529. doi: 10.1007/s12272-0130210-7

Zambrano, J. C., Carper, H. T., Rakes, G. P., Patrie, J., Murphy, D. D., Platts-Mills, T. A., et al. (2003). Experimental rhinovirus challenges in adults with mild asthma: response to infection in relation to IgE. J. Allergy Clin. Immunol. 111, 1008-1016. doi: $10.1067 /$ mai.2003.1396

Conflict of Interest Statement: The authors declare that the research was conducted in the absence of any commercial or financial relationships that could be construed as a potential conflict of interest.

Received: 30 March 2014; accepted: 28 April 2014; published online: 26 May 2014. Citation: Saraya T, Kurai D, Ishii H, Ito A, Sasaki Y, Niwa S, Kiyota N, Tsukagoshi H, Kozawa K, Goto H and Takizawa H (2014) Epidemiology of virus-induced asthma exacerbations: with special reference to the role of human rhinovirus. Front. Microbiol. 5:226. doi: 10.3389/fmicb.2014.00226

This article was submitted to Virology, a section of the journal Frontiers in Microbiology. Copyright (c) 2014 Saraya, Kurai, Ishii, Ito, Sasaki, Niwa, Kiyota, Tsukagoshi, Kozawa, Goto and Takizawa. This is an open-access article distributed under the terms of the Creative Commons Attribution License (CC BY). The use, distribution or reproduction in other forums is permitted, provided the original author(s) or licensor are credited and that the original publication in this journal is cited, in accordance with accepted academic practice. No use, distribution or reproduction is permitted which does not comply with these terms. 